\title{
Flow structure and variability in the subtropical Indian Ocean: Instability of the South Indian Ocean Countercurrent
}

\author{
V. Palastanga, ${ }^{1}$ P. J. van Leeuwen, ${ }^{1}$ M. W. Schouten, ${ }^{2}$ and W. P. M. de Ruijter ${ }^{1}$ \\ Received 16 November 2005; revised 18 August 2006; accepted 6 September 2006; published 3 January 2007.
}

[1] The origin of the eddy variability around the $25^{\circ} \mathrm{S}$ band in the Indian Ocean is investigated. We have found that the surface circulation east of Madagascar shows an anticyclonic subgyre bounded to the south by eastward flow from southwest Madagascar, and to the north by the westward flowing South Equatorial Current (SEC) between $15^{\circ}$ and $20^{\circ} \mathrm{S}$. The shallow, eastward flowing South Indian Ocean Countercurrent (SICC) extends above the deep reaching, westward flowing SEC to $95^{\circ} \mathrm{E}$ around the latitude of the high variability band. Applying a two-layer model reveals that regions of large vertical shear along the SICC-SEC system are baroclinically unstable. Estimates of the frequencies (3.5-6 times/year) and wavelengths (290-470 km) of the unstable modes are close to observations of the mesoscale variability derived from altimetry data. It is likely then that Rossby wave variability locally generated in the subtropical South Indian Ocean by baroclinic instability is the origin of the eddy variability around $25^{\circ} \mathrm{S}$ as seen, for example, in satellite altimetry.

Citation: Palastanga, V., P. J. van Leeuwen, M. W. Schouten, and W. P. M. de Ruijter (2007), Flow structure and variability in the subtropical Indian Ocean: Instability of the South Indian Ocean Countercurrent, J. Geophys. Res., 112, C01001, doi:10.1029/2005JC003395.

\section{Introduction}

[2] It is well known from satellite altimetry that the variability of the South Indian Ocean comprises a range of frequencies from interannual to subannual timescales [e.g., de Ruijter et al., 2005]. The rms of the sea surface height (SSH) in the South Indian Ocean shows a local maximum off Sumatra extending into the basin along $12^{\circ} \mathrm{S}$, and a second area of high variability around $25^{\circ} \mathrm{S}$ extending eastward to the Australian coast and westward to east of Madagascar (Figure 1). The SSH variance off Java to $90^{\circ} \mathrm{E}$ is related to baroclinic instability of the South Equatorial Current (SEC) at a period of 40-80 days [Feng and Wijffels, 2002], while to the east the variance is attributed to annual Rossby waves [Perigaud and Delecluse, 1992; Morrow and Birol, 1998], interannual SSH anomalies related to the Indian Ocean dipole (IOD) as well as El Niño-Southern Oscillation (ENSO) teleconnections [Xie et al., 2002]. In the latitude band $20^{\circ}-30^{\circ} \mathrm{S}$ evidence for semiannual [Morrow and Birol, 1998] and 4-5 times/year [Schouten et al., 2002] westward propagating Rossby waves was found. Analyzing a simple two-layer model, Birol and Morrow [2001] concluded that the quasi-semiannual Rossby waves (i.e., periods between 150 and 180 days) are connected to variations in the eastern boundary pycnocline. Moreover, Birol and Morrow [2003] presumed that the semiannual coastal Kelvin waves along Australia might

\footnotetext{
${ }^{1}$ Institute for Marine and Atmospheric Research, Utrecht University, Utrecht, Netherlands.

${ }^{2}$ Royal Netherlands Institute for Sea Research, Texel, Netherlands.

Copyright 2007 by the American Geophysical Union. 0148-0227/07/2005JC003395\$09.00
}

be remotely forced, i.e., by equatorial Pacific wind anomalies. However, the forcing of the observed 4-5 times/year waves in the $25^{\circ} \mathrm{S}$ band east of Madagascar was not identified. In the present study, we further investigate the causes of the variability in this subtropical band.

[3] The eastern part of the subtropical Indian Ocean is also characterized by significant mesoscale eddy activity associated with eddies pinched off from the Leeuwin Current west off Australia. Combining hydrographic observations and altimetry data, Fang and Morrow [2003] could track Leeuwin Current anticyclonic eddies propagating westward between $20^{\circ}-32^{\circ} \mathrm{S}$. Interaction with bottom topography seems to induce a slowing down and decay of the eddy amplitudes. Overall, the eddy signals are lost west of $90^{\circ} \mathrm{E}$.

[4] South of Madagascar eddies have been tracked with altimetry propagating (south) westward towards the Agulhas Current [Gründlingh, 1995; Schouten et al., 2002]. Thereafter, they may have an impact on the shedding of Agulhas Rings [Schouten et al., 2002]. Recently, large deepreaching dipoles (i.e., vortex pairs) were discovered and measured hydrographically in this region [de Ruijter et al., 2004]. They also propagate into the Agulhas Retroflection region and trigger the shedding of Agulhas rings. Analyzing 6 years of altimetry data, de Ruijter et al. [2004] could only follow three of these dipoles upstream as pairs to the southern tip of the Mascarene ridge $\left(23^{\circ} \mathrm{S}, 55^{\circ} \mathrm{E}\right)$; in most cases, cyclonic vortices formed as lee eddies at the southern tip of Madagascar, whereas anticyclones were first observed in the region east or south of Madagascar. Schouten et al. [2002] detected a dominant frequency of 4-5 times/year in the eddy variability around Madagascar, suggesting a modulation in the eddy-formation processes by the arrival of 


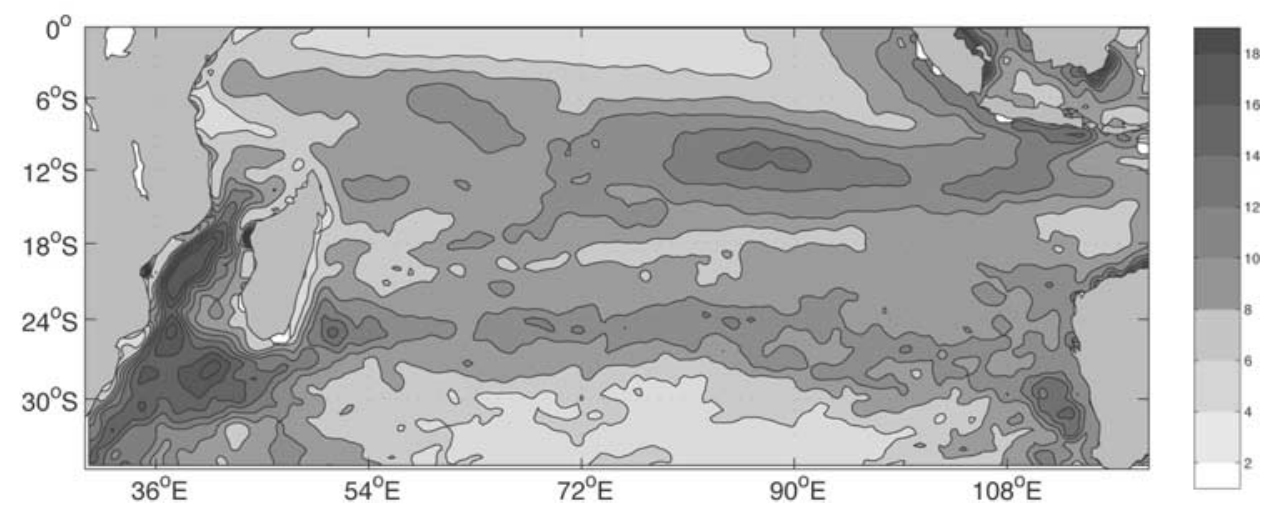

Figure 1. Rms of the sea surface height (SSH) variability in the South Indian Ocean from the combined T/P-ERS data set. Weekly SSH data from October 1992 to January 2004 are used. Units in $\mathrm{cm}$. East of Madagascar, two bands of enhanced variability are clearly visible around $12^{\circ} \mathrm{S}$ and $24^{\circ} \mathrm{S}$.

Rossby waves at $12^{\circ} \mathrm{S}$ and $27^{\circ} \mathrm{S}$ at the same subannual frequency. At interannual timescales, the eddy kinetic energy in the Mozambique Channel is correlated with the IOD phases [Palastanga et al., 2006].

[5] Baroclinic instability processes appear to be important in explaining the observed eddy variability in subtropical regions of other ocean basins [Halliwell et al., 1994; Qiu, 1999; Qiu and Chen, 2004]. Stammer [1997] pointed out that this might be a general characteristic of the extratropical oceans: the analysis of global SSH wavenumber spectra showed that at midlatitudes maximum energy is found at a wavelength related to the first mode baroclinic Rossby radius of deformation, suggesting the dominance of baroclinic instability as a source for mesoscale variability. In the center of the subtropical gyres of the Pacific Ocean, eastward quasi-zonal currents of thermal origin have been documented [Qiu and Chen, 2004], and were simulated with numerical models [Takeuchi, 1986]. Using a $2 \frac{1}{2}$ layer model, Qiu [1999] and Qiu and Chen [2004] studied the baroclinic instability of these quasi-zonal jets in the North and South Pacific, respectively. Their findings suggest that seasonal variations in the intensity of the instability can explain the seasonal variations observed in the eddy kinetic energy. The question that arises is to what degree the variability in the subtropical band east of Madagascar can be explained in a similar way.

[6] The first objective of this study is to describe and analyze the mean circulation of the subtropical Indian Ocean between $20^{\circ}$ and $30^{\circ} \mathrm{S}$, in particular, its vertical structure and velocity shear characteristics. The second objective is to investigate the stability characteristics of this flow. So far, the scarcity of observations in the central part of the subtropical gyre of the South Indian Ocean has limited a detailed analysis of the currents and their variability. In this study we combine the available hydrographic data with altimetry observations to investigate the structure of the flow and show a connection between the subtropical South Indian Ocean upper layer circulation and the local eddy-field.

[7] The paper is organized as follows. In section 2 the data sets used in this study are described, and section 3 briefly discusses the characteristics of the subtropical eddy variability derived from altimetry. Section 4 deals with the description of the mean flow structure along the $20^{\circ}-30^{\circ} \mathrm{S}$ band. The instability of this flow is analyzed in section 5 using two-layer model dynamics. A summary and discussion close the paper.

\section{Data}

[8] The climatological data used in this study consist of temperature and salinity observations of the South Indian Ocean available in the World Ocean Atlas 2001 (WOA01) database [Conkright et al., 2002]. These observations were objectively analyzed and interpolated onto a 1-degree resolution grid extending from the surface to a depth of $5500 \mathrm{~m}$. The sampling in the subtropical South Indian Ocean, especially far from the coast, is rather poor. The number of surface temperature observations along $25^{\circ} \mathrm{S}$ within 1-degree boxes lies on average between 20 and 60 , in particular observations decrease from 60 near $65^{\circ} \mathrm{E}$ to about 15 near $90^{\circ} \mathrm{E}$. The number of surface salinity observations is larger in the western than in the central South Indian Ocean basin, with most of the observations confined to meridional sections located along $65^{\circ} \mathrm{E}, 80^{\circ} \mathrm{E}$ and $90^{\circ} \mathrm{E}$ (i.e., on average 10 to 15 observations are found along $25^{\circ} \mathrm{S}$ ).

[9] Additional temperature and salinity data were obtained from three World Ocean Circulation Experiment (WOCE) hydrographic sections in the Indian Ocean. These comprise the IO7N and $\mathrm{IO} 7 \mathrm{C}$ sections along $55^{\circ} \mathrm{E}$ from $12^{\circ} \mathrm{S}$ to $29^{\circ} \mathrm{S}$ [Donahue and Toole, 2003]; the I8N section along $80^{\circ} \mathrm{E}$, from $24^{\circ} \mathrm{S}$ to $6^{\circ} \mathrm{N}$ [Talley and Baringer, 1997]; and the I9N section along $95^{\circ} \mathrm{E}$ from $45^{\circ} \mathrm{S}$ to $5^{\circ} \mathrm{S}$ [Gordon, 1995].

[10] We use SSH measurements from the TOPEX/Poseidon (T/P) and ERS satellite missions combined and interpolated onto a $1 / 3^{\circ} \times 1 / 3^{\circ}$ grid by the Collecte Localisation Satellites (CLS) Space Oceanography Division, France. The data span the period October 1992 to January 2004, with a time spacing of one week.

\section{SSH Variability From Altimetry}

[11] To highlight mesoscale eddy variability in the altimetry data, a high pass Lanczos filter [Duchon, 1979] with a 35 weeks ( $\sim 8$ months) cutoff period was applied to the weekly SSH. As the filter response function varies from 1 to 0 at periods from 18 to 35 weeks, by filtering we expect to 


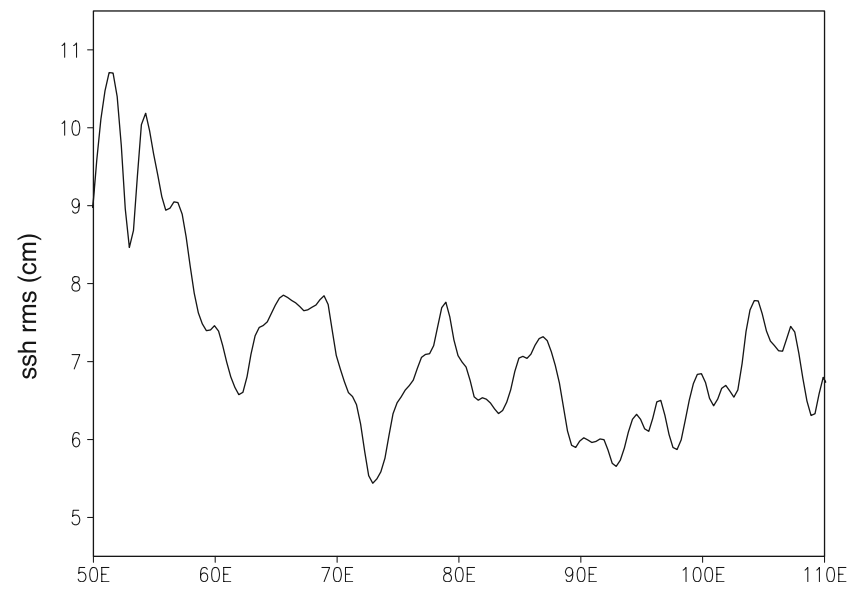

Figure 2. Rms of the high pass filtered $\mathrm{SSH}$ along $24^{\circ} \mathrm{S}$ in the South Indian Ocean. A filter with a cutoff period of 8 months was applied to the weekly SSH field from the combined T/P-ERS data set.

remove the steric height annual variability ( $\sim 52$ weeks) [Stammer, 1997] and to reduce the semiannual signal ( $\sim 25$ weeks) observed along the latitude band $20^{\circ}-30^{\circ} \mathrm{S}$ [Morrow and Birol, 1998]. The rms of the high passed SSH shows a band of high variability around $25^{\circ} \mathrm{S}$ like the unfiltered data (Figure 1), but with relative maxima more clearly outstanding near $67^{\circ} \mathrm{E}, 80^{\circ} \mathrm{E}, 87^{\circ} \mathrm{E}$, and $105^{\circ} \mathrm{E}$ (Figure 2). Inspection of the time-longitude diagram of the high passed SSH reveals wavelike westward propagating features along this band (not shown).

[12] To analyze the dominant frequencies of the SSH variability along $25^{\circ} \mathrm{S}$, a spectral analysis was performed around $100^{\circ} \mathrm{E}, 80^{\circ} \mathrm{E}$, and $65^{\circ} \mathrm{E}$. Figure $3 \mathrm{a}$ shows that near $100^{\circ} \mathrm{E}$ the dominant variability is found at around a period of 19 weeks ( 2.5 times/year), while in the central and western basin the spectral peak occurs at around 1415 weeks ( $\sim 4$ times/year). In particular, this shorter period appears to dominate the spectra over the areas of maximum variability west of $90^{\circ} \mathrm{E}$ (Figure 2). The presence of variability around 4-5 times/year is consistent with the observations of Schouten et al. [2002]. Energy present at longer periods (22-24 weeks) is probably related to the quasisemiannual variability forced at the eastern boundary [Birol and Morrow, 2001].

[13] To estimate the spatial scales associated with the subtropical eddy variability, the data were high pass filtered with a cut off wavelength of $700 \mathrm{~km}$ and SSH wavenumberspectra along $25^{\circ} \mathrm{S}$ and between $50^{\circ} \mathrm{E}-110^{\circ} \mathrm{E}$ were computed. Figure $3 \mathrm{~b}$ shows a dominant peak at a wavelength of around $440 \mathrm{~km}$, whereas for higher wavenumbers the energy closely follows a $k^{-3}$ relation. Stammer [1997] noted that this type of cutoff in the spectra is associated with the length scale at which the maximum baroclinic instability occurs. Moreover, the energy decay in the spectra as a power-function of the wavenumber $k$ is consistent with theories of baroclinic instability and geostrophic turbulence [Pedlosky, 1987]. In the Indian Ocean around $25^{\circ} \mathrm{S}$ the wavelength associated with the first baroclinic Rossby radius of deformation is $2 \pi R_{0} \sim 330 \mathrm{~km}$ [Chelton et al., 1998]. This is in good agreement with the SSH spectral maximum, if one considers that real mesoscale features tend to be larger than those predicted by linear theories of baroclinic instability [Pedlosky, 1987]. The peak in the spectra at a wavelength of around $590 \mathrm{~km}$ (Figure 3b) might be related to the quasi-semiannual waves (i.e., wavelengths of 300-500 km) observed by Morrow and Birol [1998].

\section{Mean Flow Structure}

[14] Owing to the scarcity of observations in the center of the subtropical gyre, the flow structure between $20^{\circ}-30^{\circ} \mathrm{S}$

(a)
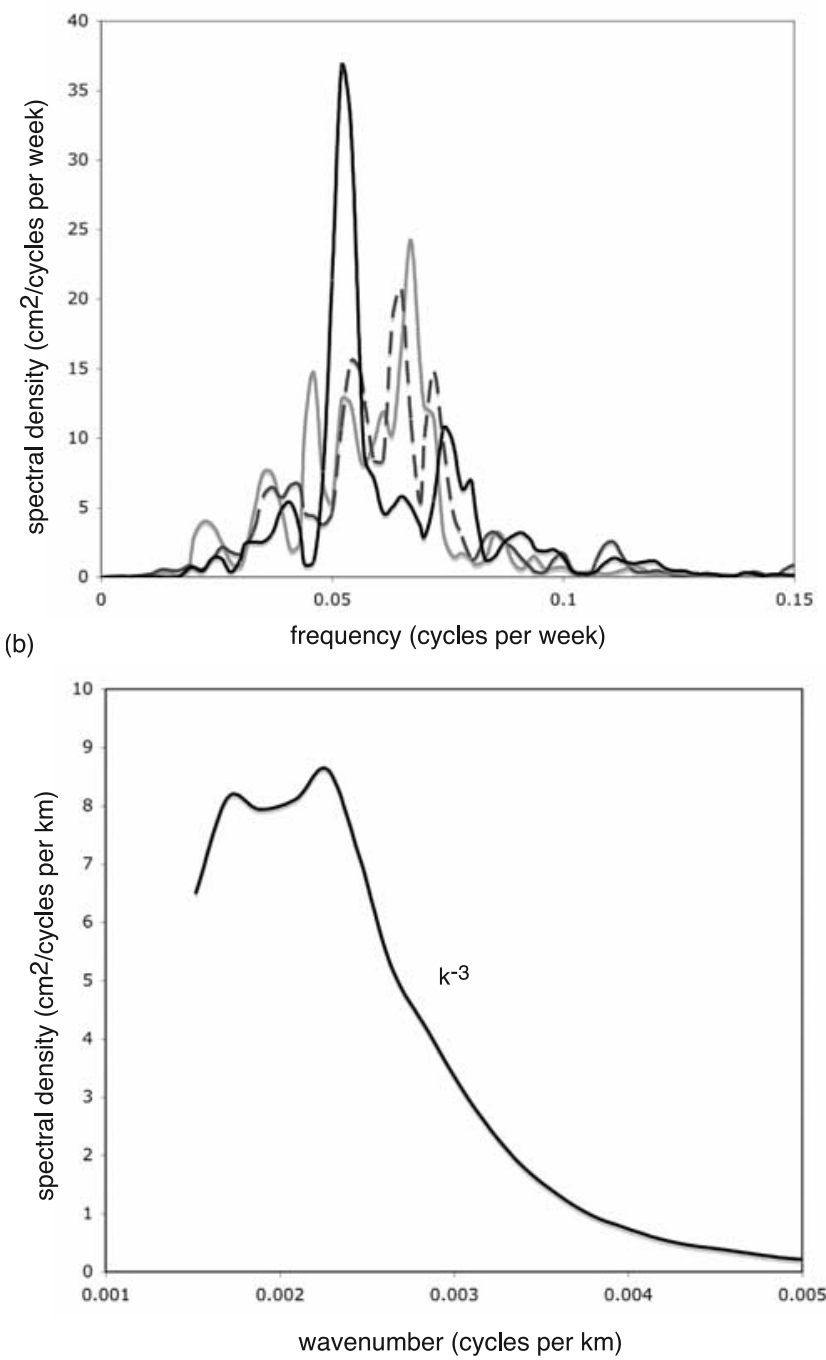

Figure 3. (a) Frequency spectra of the high pass filtered SSH from the combined T/P-ERS data set in three regions along $25^{\circ} \mathrm{S}$, namely, at $100^{\circ} \mathrm{E}$ (solid black line), $80^{\circ} \mathrm{E}$ (dashed line), and $65^{\circ} \mathrm{E}$ (solid gray line). The dominant frequency changes from 2.5 times/year in the east to 4 times/year in the central and western basin. (b) Wavenumber spectra of the SSH data along $25^{\circ} \mathrm{S}$ and between $50^{\circ}$ and $110^{\circ} \mathrm{E}$. Weekly SSH were high pass filtered with a cut off wavelength of $700 \mathrm{~km}$. Energy decays at high wavenumbers as the third power law of the wavenumber, $\mathrm{k}^{-3}$. The dominant wavelength is found around $440 \mathrm{~km}$, and a second peak appears around $590 \mathrm{~km}$. 
(a)

(b)
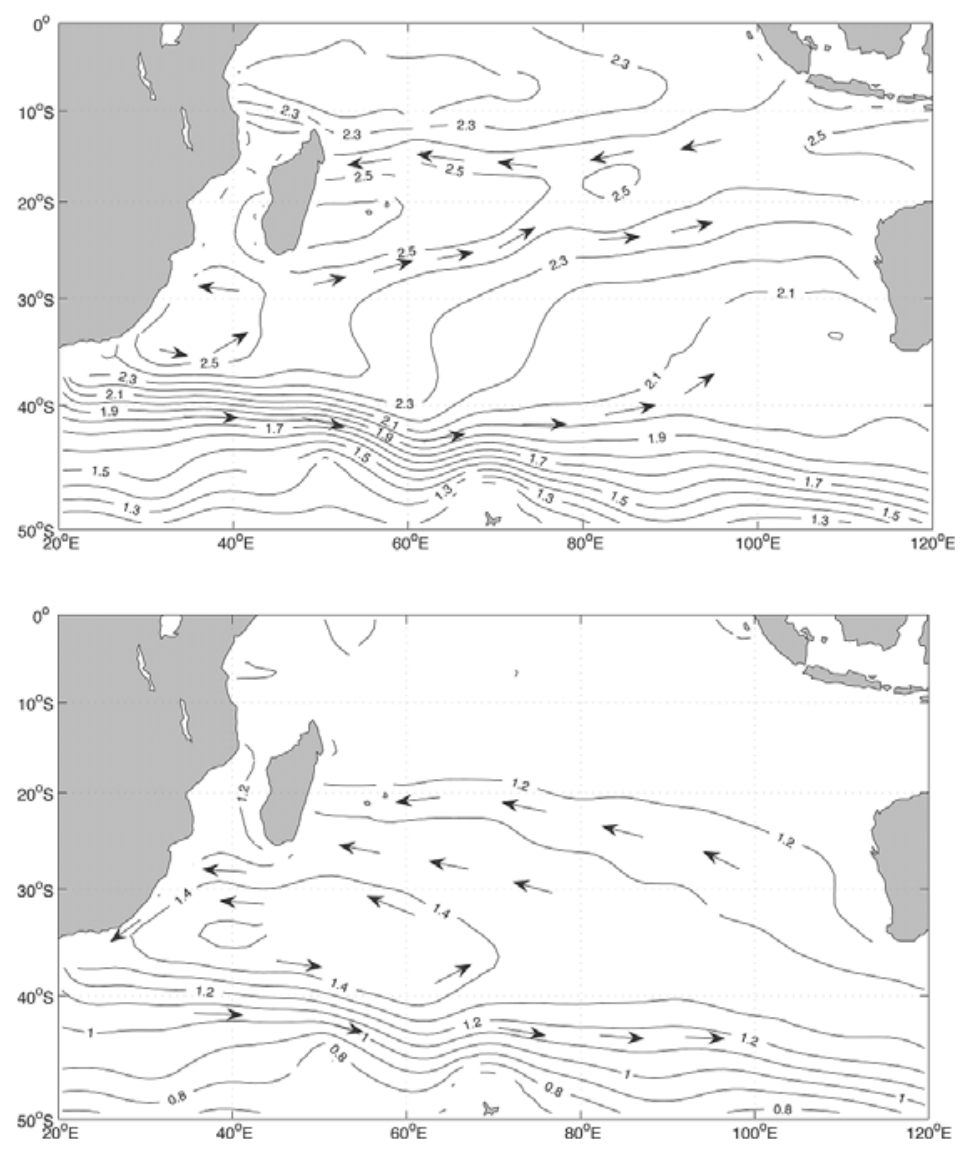

Figure 4. Dynamic topography of the South Indian Ocean relative to $2000 \mathrm{~m}$ at (a) the surface and (b) $500 \mathrm{~m}$, based on the climatological hydrographic data. Units in $\mathrm{m}^{2} / \mathrm{s}^{2}$. Contours every 0.1 units. It shows a recirculation cell east of Madagascar and general eastward flow in the upper layer south of $20^{\circ} \mathrm{S}$. At $500 \mathrm{~m}$ the flow between $20^{\circ}$ and $30^{\circ} \mathrm{S}$ is westward, as a Sverdrupian flow.

is not yet well known. On the basis of hydrographic data, Stramma and Lutjeharms [1997] estimated the idealized transport of the subtropical gyre over the upper $1000 \mathrm{~m}$. They showed that the westward return flow in the gyre is found in the subtropical basin from $40^{\circ} \mathrm{S}$ up to the SEC latitude, and as part of a recirculation cell in the southwest corner of the basin (see their Figure 7). Dynamic topography maps in the atlas by Wyrtki [1971], as well as the analysis by Reid [2003], indicates, however, that east of Madagascar there is a surface eastward flow. In this section we analyze in detail the structure of the flow in the South Indian Ocean around $25^{\circ} \mathrm{S}$ from the surface down to about $1000 \mathrm{~m}$. Although it is expected that seasonal changes can be important in the near surface circulation, because of the lack of observations, we limit the description to the mean pattern. Comments related to the seasonal variability are included in the discussion section.

[15] The climatological dynamic topography at the surface relative to $2000 \mathrm{~m}$ (Figure 4a) shows the pattern of the subtropical gyre with a recirculation cell in the southwestern basin around $30^{\circ} \mathrm{S}$ [Stramma and Lutjeharms, 1997], and an anticyclonic cell east of Madagascar. The latter is bounded to the north by the westward flowing SEC, roughly between $10^{\circ}-20^{\circ} \mathrm{S}$, and to the south by an eastward flow from south Madagascar up to $75^{\circ} \mathrm{E}$. The eastward flow continues between $20^{\circ}-30^{\circ} \mathrm{S}$ from the central basin to Australia, and seems connected to the South Indian Ocean Current, which constitutes the southern limit of the subtropical gyre at around $\sim 40^{\circ} \mathrm{S}$ [Stramma, 1992]. This shallow, quasizonal eastward flow along $25^{\circ} \mathrm{S}$ has not been previously documented in detail. It is noteworthy that the location of this jet is similar to that of the subtropical countercurrents observed in the North and South Pacific [Qiu, 1999; Qiu and Chen, 2004], supporting the idea of a dynamically similar permanent current in the South Indian Ocean subtropical gyre. By analogy with the Pacific Ocean we will hereafter refer to the Indian Ocean eastward jet as the South Indian Ocean Countercurrent (SICC). At $500 \mathrm{~m}$ (Figure 4b), the flow between $20^{\circ}-30^{\circ} \mathrm{S}$ is westward in agreement with the large scale Sverdrup flow forced by the wind stress curl, and the southwestern recirculation cell extends up to $70^{\circ} \mathrm{E}$.

[16] A geostrophic velocity section at $65^{\circ} \mathrm{E}$ (Figure 5a) based on climatology, shows the vertical structure of the flow east of Madagascar. The eastward jet is confined to the upper $250 \mathrm{~m}$ in the latitude band $20^{\circ}-35^{\circ} \mathrm{S}$, with its core around $25^{\circ} \mathrm{S}$ and surface velocities up to $0.06 \mathrm{~m} / \mathrm{s}$. It flows above westward velocities of about $-0.02 \mathrm{~m} / \mathrm{s}$ associated with the southward extension of the SEC between depths of 350 and $1100 \mathrm{~m}$. This vertical structure characterizes the flow between $50^{\circ}$ and $95^{\circ} \mathrm{E}$. East of $75^{\circ} \mathrm{E}$ the eastward jet 
(a)

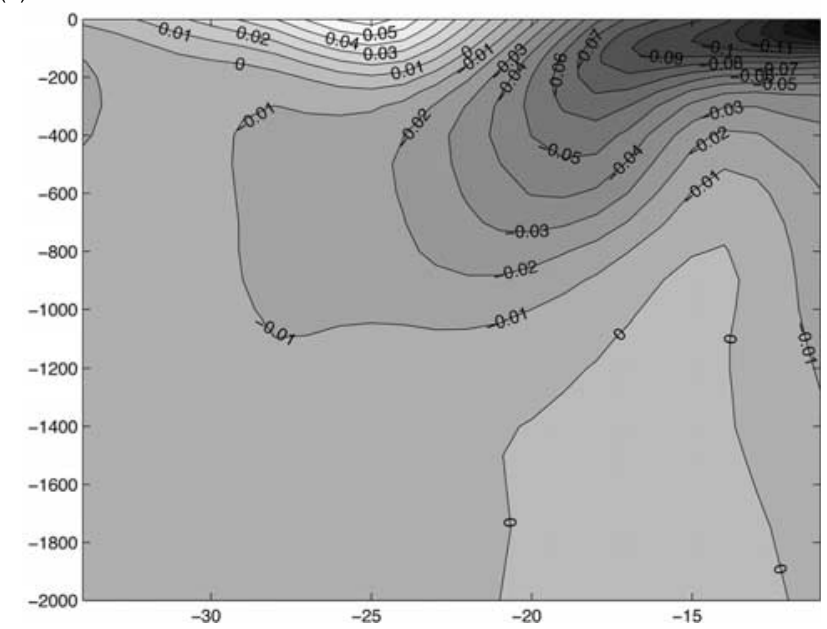

(b)

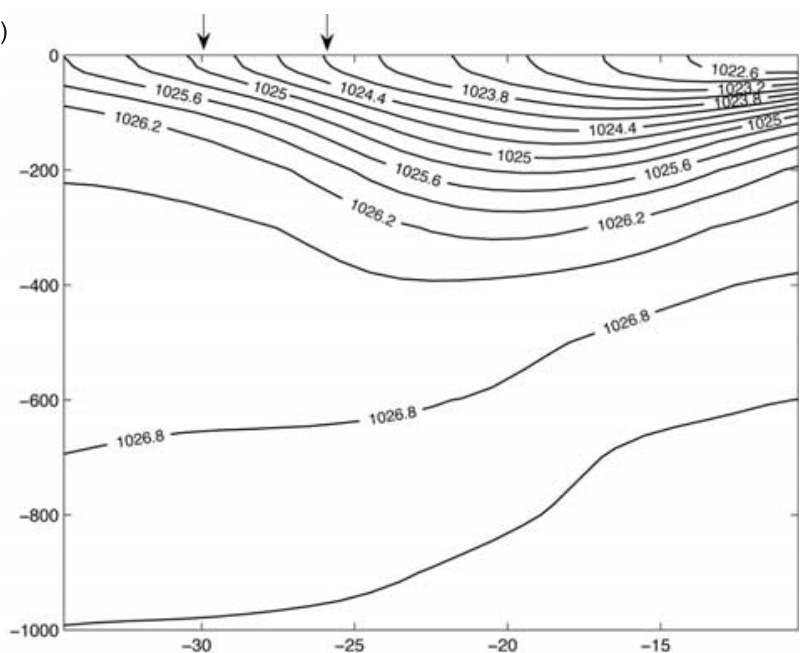

Figure 5. Geostrophic zonal flow structure along $65^{\circ} \mathrm{E}$ computed from climatological temperature and salinity data relative to $2000 \mathrm{~m}$. Contours every $0.01 \mathrm{~m} / \mathrm{s}$. Light (dark) shaded correspond to the eastward SICC (westward SEC). The SICC extends in the latitude band $20^{\circ}-35^{\circ} \mathrm{S}$, overlying the southward extension of the SEC at deep levels in the subtropical gyre. (b) Meridional section of potential density along $65^{\circ} \mathrm{E}$ in the South Indian Ocean from the climatology. Units in $\mathrm{kg} / \mathrm{m}^{3}$. Contours every 0.3 units. A shallow density front exists in the latitude band $26^{\circ}-30^{\circ} \mathrm{S}$. This front lies farther north than the northern branch of the Subtropical Front (i.e., NSTF) documented by Belkin and Gordon [1996].

core moves slightly to the north. A density section at the same location (Figure 5b) shows relative high meridional gradient of the surface isopycnals between $26^{\circ} \mathrm{S}$ and $30^{\circ} \mathrm{S}$, suggesting the presence of a frontal structure in the upper 200-300 m. The SICC could be the current associated with the front in terms of thermal wind balance. An estimate of the velocity difference between the climatological flow at the surface and at a depth of $600 \mathrm{~m}$ yields relative maxima of $\sim 0.08 \mathrm{~m} / \mathrm{s}$ near $55^{\circ} \mathrm{E}, 65^{\circ} \mathrm{E}$ and $83^{\circ} \mathrm{E}$, and minima near $75^{\circ} \mathrm{E}$ and $90^{\circ} \mathrm{E}$ (Figure 6), which are mainly related to the intensity of the climatological surface current.
[17] To estimate the actual strength of this frontal system, geostrophic velocities were also derived along the three WOCE hydrographic sections. Along $55^{\circ} \mathrm{E}$ the velocity section shows two alternating eastward and westward velocity cores between $22^{\circ}$ and $26^{\circ} \mathrm{S}$, extending from the surface to about $900 \mathrm{~m}$ deep, which seem to be due to two anticyclonic eddies (not shown). Additionally, lowered acoustic Doppler current profiler (LADCP) data available at the time of the cruise confirm the eastward-westward reversal of surface velocities around $25^{\circ} \mathrm{S}$, with speeds of $0.35 \mathrm{~m} / \mathrm{s}$. In the section along $95^{\circ} \mathrm{E}$ there is also an indication of an anticyclonic eddy around $24^{\circ} \mathrm{S}$. Because of the presence of the eddies, these two sections were not considered for further analysis. The section along $80^{\circ} \mathrm{E}$ extended to the south as far as $24^{\circ} \mathrm{S}$. Between $22^{\circ}$ and $24^{\circ} \mathrm{S}$ a core of eastward velocities is seen in the upper $200 \mathrm{~m}$, flowing over a westward flow. Velocities at the surface reach $0.28 \mathrm{~m} / \mathrm{s}$ and show a minimum of about $-0.025 \mathrm{~m} / \mathrm{s}$ near $500 \mathrm{~m}$ (Figure 7a). Comparison with the vertical structure obtained from the climatology at that location indicates good qualitative agreement, although there are differences in the depth extension of the eastward and westward flows, and in the magnitude of surface velocities. In particular, the actual surface velocities are almost one order of magnitude larger than the climatological ones, and the velocity difference between 0 and $600 \mathrm{~m}$ is greater in the synoptic data by a factor of 4 (Figures $7 \mathrm{a}$ and $7 \mathrm{~b}$ ).

[18] The subtropical countercurrents in the Pacific Ocean are closely related to the location of the Subtropical Front. They originate from the superposition of the baroclinic circulation driven by the meridional temperature gradient across the front, and the wind driven barotropic flow [Takeuchi, 1986]. Belkin and Gordon [1996] analyzed the fronts of the South Indian Ocean south of $30^{\circ} \mathrm{S}$. They defined the northern branch of the Subtropical Front (NSTF) over the sector $30^{\circ}-38^{\circ} \mathrm{S}, 60^{\circ}-90^{\circ} \mathrm{E}$ to be the southern boundary of the warm, salty water of the central subtropical gyre. Inspection of the mean sea surface temperature (SST) fields from climatology shows a band of

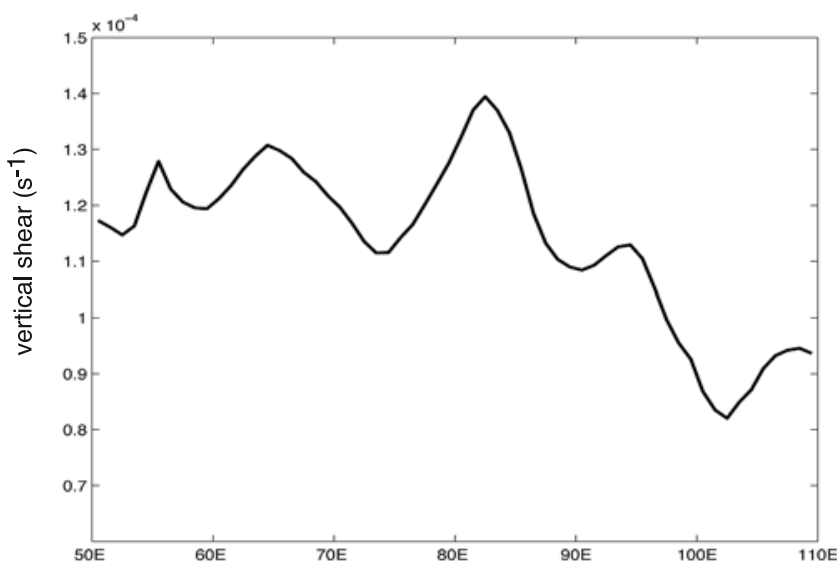

Figure 6. Vertical shear of the (climatological) SICC-SEC system along $25^{\circ} \mathrm{S}$ in the South Indian Ocean. The shear is computed as the difference between velocities at the surface and at $600 \mathrm{~m}$, divided by the layer depth. Relative maxima are found near $55^{\circ} \mathrm{E}, 65^{\circ} \mathrm{E}$, and $82^{\circ} \mathrm{E}$, although the variations are small. 
(a)

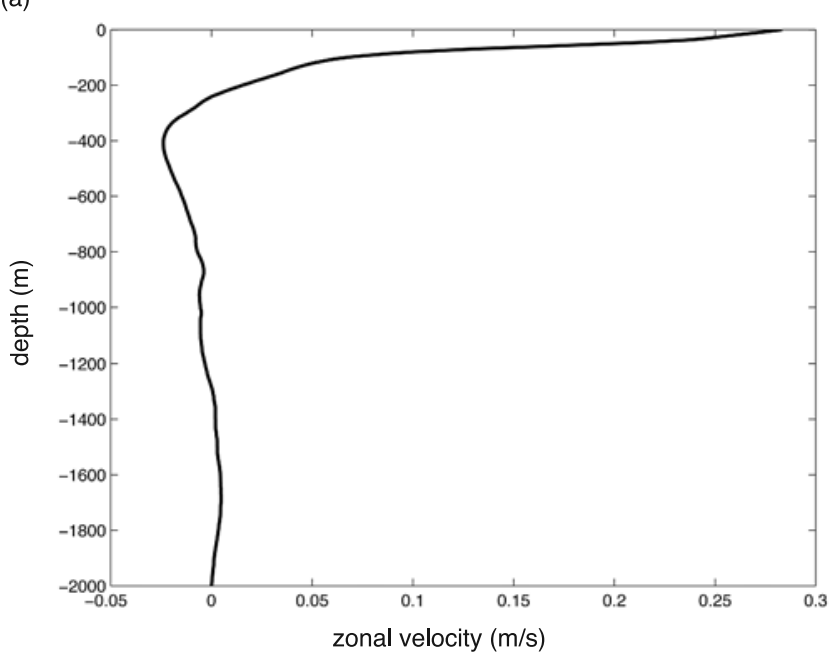

(b)

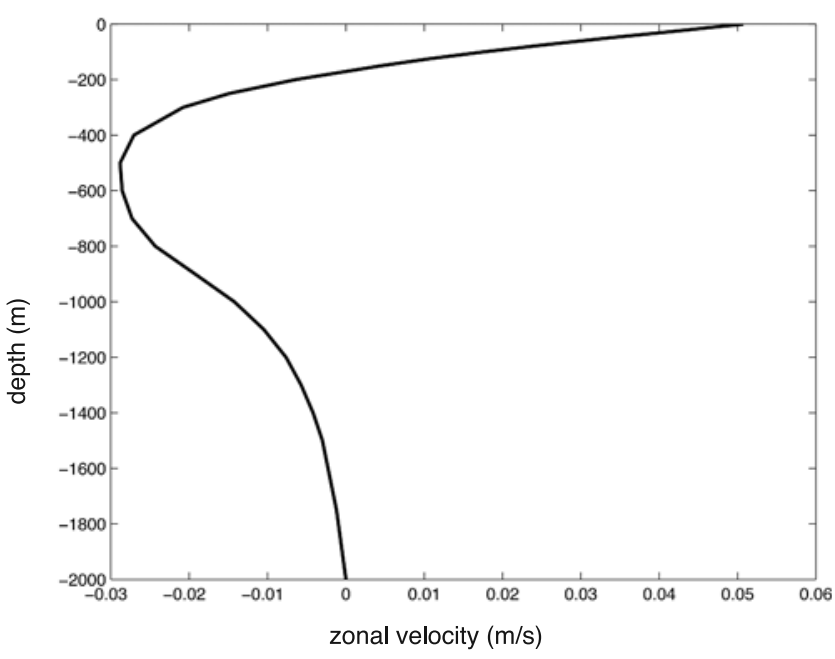

Figure 7. (a) Geostrophic zonal velocity profile at $80^{\circ} \mathrm{E}$, $24^{\circ} \mathrm{S}$, in the upper $2000 \mathrm{~m}$ from a WOCE hydrographic section. (b) Same as Figure 7a, but from climatological data. Note the difference in velocity scale. This shows that climatology underestimates significantly the magnitude of the surface, eastward velocities. The velocity difference computed between 0 and $600 \mathrm{~m}$ is about $0.3 \mathrm{~m} / \mathrm{s}$ in the WOCE data, but lower by a factor 4 in the climatology $(\sim 0.08 \mathrm{~m} / \mathrm{s})$.

relatively high meridional SST gradients extending with a southeastward tilt from $45^{\circ} \mathrm{E}, 27^{\circ} \mathrm{S}$ towards Australia (Figure 8a). Analysis of SST from satellite data supports the existence of a similar basin temperature front between $27^{\circ}$ and $35^{\circ} \mathrm{S}$. In the central basin, these temperature gradients seem connected to the NSTF of Belkin and Gordon [1996]. The meridional salinity gradients from climatology indicate a frontal zone east of $75^{\circ} \mathrm{E}$ between $20^{\circ}$ and $26^{\circ} \mathrm{S}$ (Figure 8b) that corresponds to the South Indian Tropical Front [Tchernia, 1980], which separates salty waters of the central subtropical Indian Ocean from the fresher waters of the eastern tropical Indian Ocean. As a consequence, a secondary density front exists in the band $20^{\circ} \mathrm{S}-30^{\circ} \mathrm{S}$ (i.e., north of the NSTF of Belkin and Gordon [1996]) extending with a northeastward tilt from southeast Madagascar to the eastern subtropical basin. Whether (and how) this subtropical frontal zone is linked to the origin of the SICC deserves further investigation that will be left for future studies.

[19] Another important aspect of the SICC to be investigated is its connection to the western boundary current that closes the surface anticyclonic circulation east of Madagascar (Figure 4a), i.e., the East Madagascar Current (EMC). The fate of the EMC after separating from the Madagascar coast has been a subject of discussion. Based on the available hydrographic observations Lutjeharms [1976] suggested that the surface flow south of Madagascar was eastward, leading later to the suggestion of an EMC retroflection similar to that of the Agulhas current [Lutjeharms, 1988]. However, based on chlorophyll data, Quartly and Srokosz [2004] found indications of different EMC regimes, sometimes corresponding to a retroflection, in other cases to a westward continuation towards the African coast. The eastward flow we observed from the climatology near the southwestern tip of Madagascar (Figure 4a) seems consistent with the observations of Lutjeharms [1976]. Farther east, the SICC could support the existence of an EMC retroflection and/or an eastward EMC return flow into the ocean interior. However, the SICC is shallow compared to the vertical extension of the EMC, so only the near-surface part of the EMC would be involved in such a retroflection.

[20] In summary, both climatology and WOCE data reveal the SICC to be a shallow eastward current extending along the South Indian Ocean subtropical gyre over the westward flow of the SEC. With this sheared flow structure, instabilities of the SICC-SEC that explain the observed subtropical variability may be induced. To check this, in the next section, we analyze the baroclinic instability of the SICC-SEC system in the context of a simple two-layer model.

\section{Stability Considerations}

[21] A simple model to study baroclinic instability was introduced by Phillips [1954]. In this approximation the ocean is represented by two layers of constant depth $H_{n}$ and density $\rho_{n}$, with meridionally independent zonal velocities $U_{n}$ in each layer $(n=1$ and 2$)$. This implies that the interface between the two layers has a constant slope. Here we adopt this approximation to represent the vertical structure of the SICC-SEC system. In the absence of friction and bottom topography, the linearized version of the quasigeostrophic potential vorticity equation [see Pedlosky, 1987] reads:

$$
\left(\frac{\partial}{\partial t}+U_{n} \frac{\partial}{\partial x}\right) q_{n}+\frac{\partial \Pi_{n}}{\partial y} \frac{\partial \phi_{n}}{\partial x}=0
$$

where $q_{n}$ is the perturbation potential vorticity, $\phi_{n}$ the perturbation stream function and $\Pi_{n}$ the mean potential vorticity in layer $n$.

[22] As $U_{1}$ and $U_{2}$ are independent of y, the normal mode solutions to equation (1), $\phi_{n}$, and the meridional gradient of the mean potential vorticity, $\Pi_{n y}$, have the form:

$$
\phi_{n}=\operatorname{Re}\left[A_{n} \sin (l y) \exp i(k x-\omega t)\right]
$$


(a)

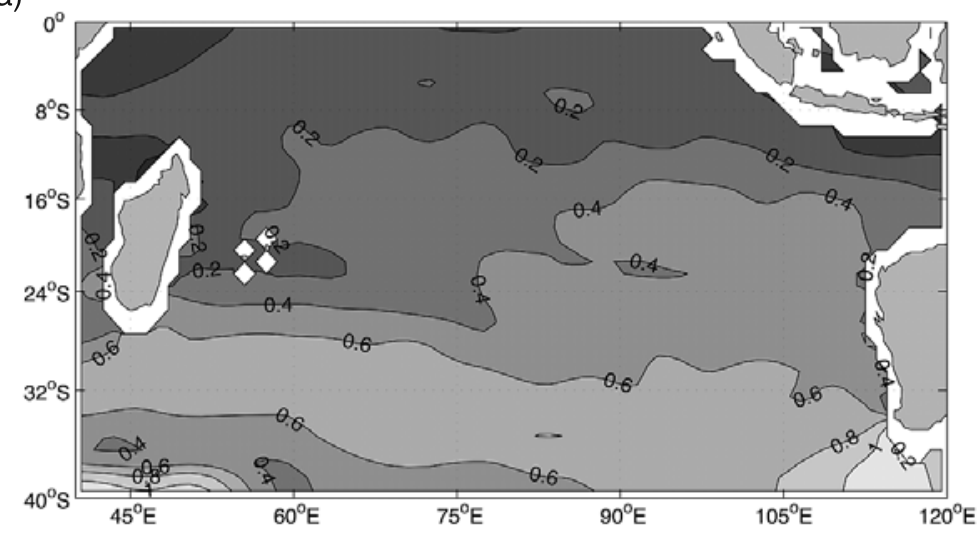

(b)

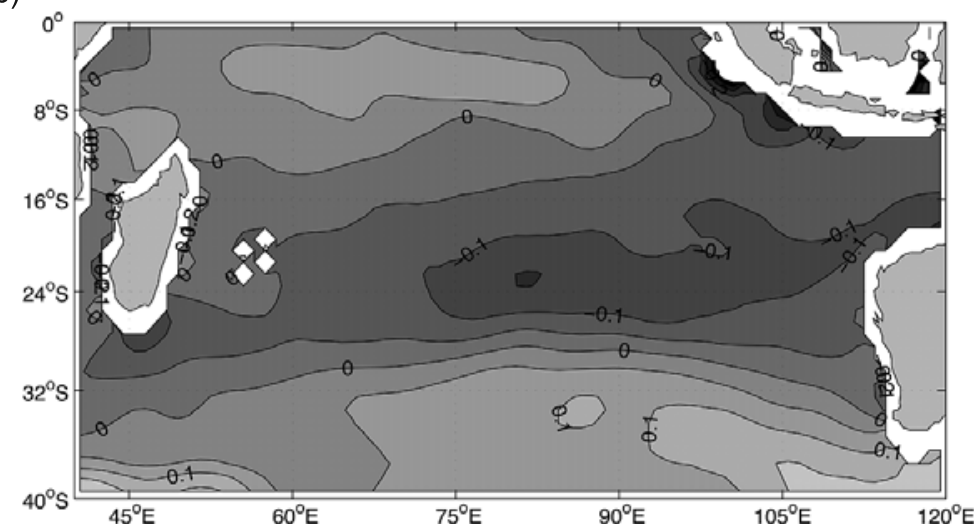

Figure 8. (a) Meridional sea surface temperature (SST) gradients in the South Indian Ocean. Units in ${ }^{\circ} \mathrm{C} / \mathrm{m}$. (b) Same as Figure 8a, but for salinity. Units in $\mathrm{psu} / \mathrm{m}$. Climatological temperature and salinity data are used. A subtropical temperature frontal zone extends southeastward from south Madagascar at $27^{\circ} \mathrm{S}$ towards southwest Australia. The salinity front seen around $24^{\circ} \mathrm{S}$ and east of $75^{\circ} \mathrm{E}$ corresponds to the South Indian Tropical Front [Tchernia, 1980].

where $l=m \pi$;

$$
\prod_{n y}=\beta-(-1)^{n} F_{n}\left(U_{1}-U_{2}\right)
$$

where

$$
F_{n}=\frac{f_{o}^{2}}{g^{\prime} H_{n}} .
$$

In the above equations, $\beta$ is the variation of the Coriolis parameter with latitude, $f_{o}$ is the Coriolis parameter at the reference latitude, $g^{\prime}$ is the reduced gravity, and $F_{n}$ is the inverse of the square of the Rossby deformation radius in each layer.

[23] Substitution of the solution (2) into equation (1) leads to a system of two ordinary differential equations for the amplitudes $A_{1}$ and $A_{2}$ [see Pedlosky, 1987]. Requiring nontrivial solutions for this system yields a quadratic equation for $c$, the complex phase speed, whose solutions are:

$$
\begin{aligned}
c & =U_{2}+\frac{U_{s} K^{2}\left(K^{2}+2 F_{2}\right)-\beta\left(2 K^{2}+F_{1}+F_{2}\right)}{2 K^{2}\left(K^{2}+F_{1}+F_{2}\right)} \\
& \pm \frac{\left[\beta^{2}\left(F_{1}+F_{2}\right)^{2}+2 \beta U_{s} K^{4}\left(F_{1}-F_{2}\right)-K^{4} U_{s}^{2}\left(4 F_{1} F_{2}-K^{4}\right)\right]^{1 / 2}}{2 K^{2}\left(K^{2}+F_{1}+F_{2}\right)}
\end{aligned}
$$

where

$$
U_{s}=U_{1}-U_{2} \text { and } K^{2}=k^{2}+l^{2} .
$$

[24] To evaluate the instability potential of the SICC-SEC system, we solved equation (5) considering zonal wave propagation (i.e., $K^{2} \sim k^{2}$ ) and using parameters derived from climatology. Inspection of the mean velocity profiles (see Figures 5 and 7) shows that values of $H_{1}$ between 200 $300 \mathrm{~m}$ and $H_{2}$ between $400-700 \mathrm{~m}$ are good choices for the depths of the upper and lower layers associated with the SICC and SEC, respectively. It is also seen from the velocity profile (Figure $7 \mathrm{~b}$ ) that the flow exhibits little variation between $400-700 \mathrm{~m}$; thus, $U_{2}$ is estimated as the average zonal flow over those depths, whereas $U_{1}$ equals the zonal velocity at the surface. As the climatology probably underestimates the actual value of the vertical shear it is reasonable to consider an upper bound estimation. The sensitivity to different estimations of the vertical shear will become clearer below. To analyze variations of the growth rate along the latitude band $20^{\circ}-35^{\circ} \mathrm{S}$, the maximum growth rate $k c_{i}$ was computed at each grid point, i.e., the spatial dependence of the vertical shear was taken into account. (Note that in the Phillips model $U_{s}$ is called the shear.) 


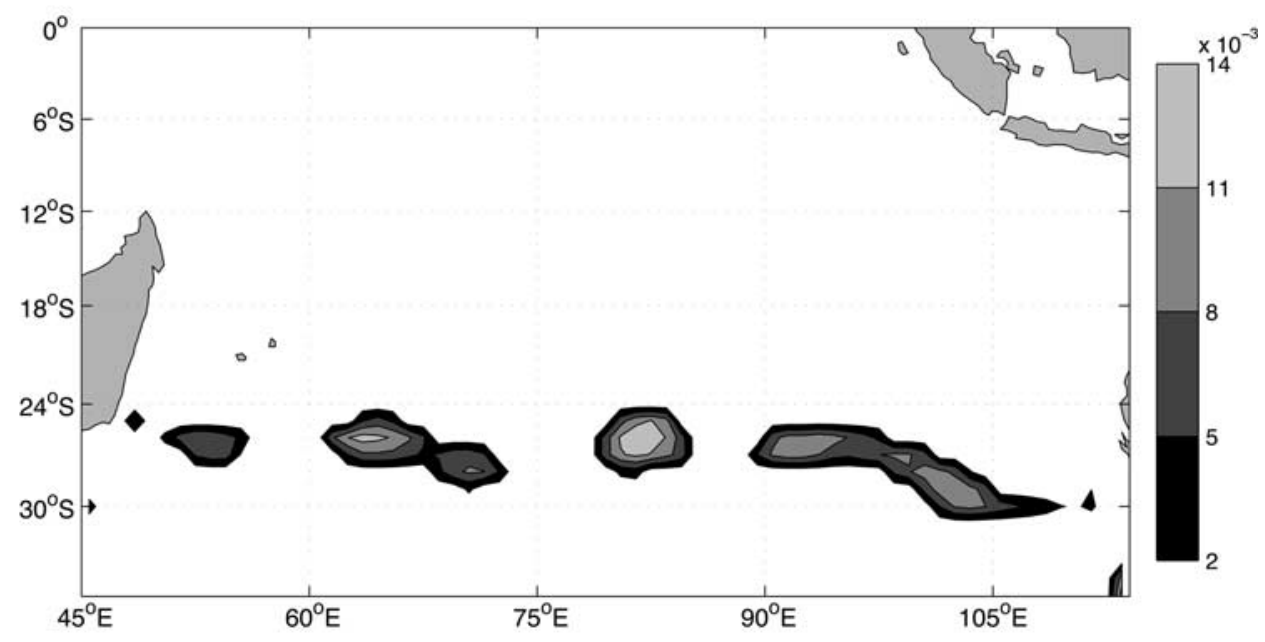

Figure 9. Maximum growth rate of the unstable modes estimated from the two-layer Phillips model equations (i.e., equation (5)), computed at each grid point over the South Indian Ocean. The model depth of the first and second layers is $250 \mathrm{~m}$ and $400 \mathrm{~m}$, respectively, and the velocity shear is estimated between the observed flow at the surface and the average flow between 400-600 m. Units in days ${ }^{-1}$. Results indicate that in the subtropical band between $24^{\circ}-30^{\circ} \mathrm{S}$ the flow is baroclinically unstable.

[25] Figure 9 shows the maximum growth rate, $k c_{i}$, when $H_{1}=250 \mathrm{~m}$ and $H_{2}=400 \mathrm{~m}$. Nonzero values are found between $24^{\circ}$ and $31^{\circ} \mathrm{S}$ and near the regions of maximum vertical shear (Figure 6). Comparison with Figure 2 shows that the instability spots also lie close to the regions of maximum variability west of $90^{\circ} \mathrm{E}$. The growth rates vary between 0.004 and 0.014 day $^{-1}$, or equivalently between $e$-folding timescales from 70 to 250 days. The wavelengths of the most unstable modes lie between 240 and $320 \mathrm{~km}$, decreasing from north to south in agreement with the variation of $R_{O}$. The southeastward tilt seen in $k c_{i}$ east of $100^{\circ} \mathrm{E}$ coincides with a shift in the SICC core towards $\sim 29^{\circ} \mathrm{S}$. The largest growth rates are found near $64^{\circ} \mathrm{E}, 26^{\circ} \mathrm{S}$ and $82^{\circ} \mathrm{E}, 26^{\circ} \mathrm{S}$ (Figure 10). They show a window of unstable wavelengths between 250 and $333 \mathrm{~km}$, with maxima around $297 \mathrm{~km}$ and $283 \mathrm{~km}$, and $e$-folding timescales between 75 and 80 days. The $e$-folding times predicted from the Phillips model are of the same order as those found for the countercurrents in the Pacific Ocean during the winter-spring season [Qiu, 1999; Qiu and Chen, 2004].

[26] The above results are quite sensitive to the thickness of the second layer. For instance, a choice of $\mathrm{H}_{2}>450 \mathrm{~m}$ makes solutions of equation (5) stable over the subtropical domain. On the other hand, reducing the depth of the first layer tends to increase the instability potential of the subtropical current system. The sensitivity to $\mathrm{H}_{2}$ is related to the necessary condition for instability in the Phillips model. For instability to occur the meridional gradient of the mean potential vorticity needs to change sign between the two layers, from equation (3) when $U_{1}>U_{2}$ this reduces to:

$$
\prod_{2 y}<0, \text { or } U_{s}>\frac{\beta}{F_{2}}=\frac{\beta g^{\prime} H_{2}}{f_{0}^{2}} .
$$

A slightly different criterion for baroclinic instability can be derived from the $2 \frac{1}{2}$ layer quasigeostrophic model equations. Qiu [1999] showed that when $U_{1}>U_{2}$, the necessary condition states that the vertical shear has to overcome the beta effect plus a factor proportional to the stratification ratio, i.e.:

$$
U_{s}>\frac{\beta}{F_{2}}+\gamma U_{2}
$$

where

$$
\gamma=\frac{\rho_{2}-\rho_{1}}{\rho_{3}-\rho_{2}}
$$

Results of equation (6) are similar to those in Figure 8, although there is a slight increase in the instability potential

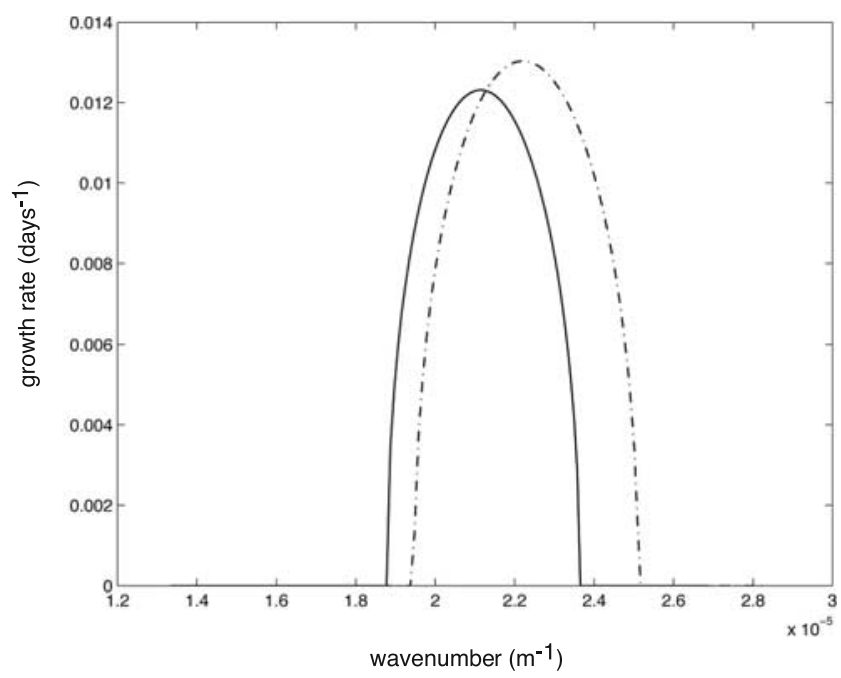

Figure 10. Growth rate as a function of the zonal wavenumber $k$ calculated from equation (5) at $64^{\circ} \mathrm{E}, 26^{\circ} \mathrm{S}$ (solid line) and at $80^{\circ} \mathrm{E}, 26^{\circ} \mathrm{S}$ (dash line). Both locations show similar $e$-folding times (between 75 days and 80 days) and wavelengths for the most unstable modes ( 290 km). 


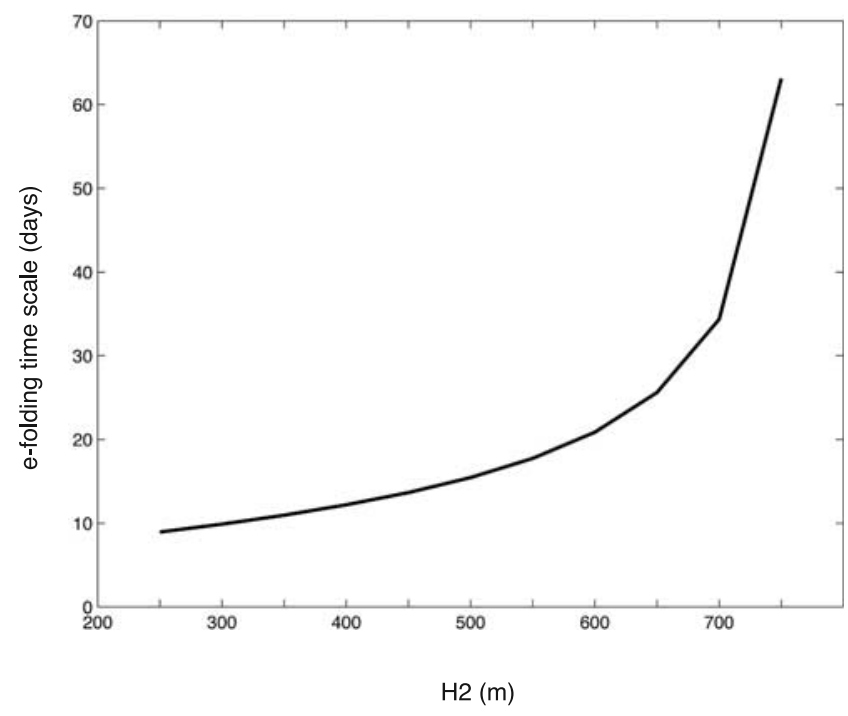

Figure 11. $E$-folding timescale of the most unstable mode as a function of the second layer depth $\mathrm{H}_{2}$ using parameters from WOCE synoptic hydrographic data at $80^{\circ} \mathrm{E}, 24^{\circ} \mathrm{S}$ (as in Figure 7a). The sensitivity of the growth rate to changes in $\mathrm{H}_{2}$ is higher if the latter varies from $650 \mathrm{~m}$ to $750 \mathrm{~m}$.

over the subtropical latitude band $24^{\circ} \mathrm{S}-31^{\circ} \mathrm{S}$. If $\mathrm{H}_{2}$ becomes larger than $450 \mathrm{~m}$, the instability is also reduced.

[27] Since the vertical shear from climatology is about 4 times smaller than that observed from synoptic hydrographic data (Figure 7), we estimated the Phillips growth rate using the zonal velocity profile available at $80^{\circ} \mathrm{E}$, $24^{\circ} \mathrm{S}$ (Figure $7 \mathrm{a}$ ). To compute $k c_{i}, U_{1}$ was estimated as the velocity averaged over the first $100 \mathrm{~m}$ and $U_{2}$ as the velocity averaged over the second layer thickness. $H_{1}$ was set equal to $250 \mathrm{~m}$, and $H_{2}$ was varied between 250 and $750 \mathrm{~m}$. (Note that the change in the vertical shear due to varying $\mathrm{H}_{2}$ is very small.) Figure 11 shows that the $e$-folding time of the most unstable waves varies slowly when $\mathrm{H}_{2}$ varies from 250 to $650 \mathrm{~m}$, but it increases sharply from $\sim 30$ to 63 days when $\mathrm{H}_{2}$ varies between 650 and $750 \mathrm{~m}$. A depth of $\sim 750 \mathrm{~m}$ for $H_{2}$ is probably the more realistic approximation of the vertical flow structure in this synoptic data set (see Figure 7a). In this case the window of unstable wavelengths is $390-470 \mathrm{~km}$, with $\mathrm{L} \sim 430 \mathrm{~km}$ for the most unstable wave. This is in agreement with the dominant spatial scale of eddy variability estimated from observations (i.e., $\sim 440 \mathrm{~km}$, Figure $3 b$ ). In addition, the frequency of the most unstable mode turns out to be around 5 times/year, though it varies in the range 3.5-6 times/year with small variations of the vertical shear (i.e., the frequency increases when the vertical shear decreases).

[28] In conclusion, the frequency range generated by the baroclinic instability as detected near $80^{\circ} \mathrm{E}, 24^{\circ} \mathrm{S}$ is close to the observed subtropical Rossby wave variability of $4-$ 5 times/year [Schouten et al., 2002]. Although the results with synoptic hydrographic data are based on a single observation of the velocity profile, they support the hypothesis that regions of maximum vertical shear around $25^{\circ} \mathrm{S}$ are baroclinically unstable. It is likely that the analysis using climatology underestimates the vertical shear and thereby the expected instability along the subtropical band.

\section{Summary and Discussion}

[29] In this study, we have analyzed the flow structure in the South Indian Ocean subtropical gyre between $20^{\circ}$ and $30^{\circ} \mathrm{S}$. The climatology shows the existence of a shallow eastward jet with its core around $25^{\circ} \mathrm{S}$, which flows over the deep reaching westward SEC. The presence of this eastward South Indian Ocean Countercurrent (SICC) is analogous to the subtropical countercurrents in the Pacific Ocean [Qiu, 1999; Qiu and Chen, 2004]. This suggests that the forcing of the SICC could be similar to that in the Pacific. The position of the northernmost branch of the Subtropical Front in the South Indian Ocean lies farther south than that in the Pacific [Belkin and Gordon, 1996]. From the climatological data we have shown the existence of a secondary, subtropical frontal zone extending across the basin between $\sim 26^{\circ}-$ $32^{\circ} \mathrm{S}$ in the west and between $\sim 20^{\circ}-27^{\circ} \mathrm{S}$ in the east. The SICC might be its associated frontal jet. The connection of the SICC to the western boundary current at that latitude, the East Madagascar current (EMC), is still unclear. Evidence for the existence of "events" of an EMC retroflection has been derived in the past from analyses of surface data [Lutjeharms, 1988; Quartly and Srokosz, 2004]. The shallow SICC could provide the mean large-scale, eastward flow to which a retroflection of the upper layers of the EMC could connect. In the future, a combination of observations and modeling studies is needed to better determine the characteristics of the SICC, its forcing and variability.

[30] The stability of the SICC-SEC vertical flow structure was analyzed using the Phillips two-layer model [Phillips, 1954]. We have shown that the SICC-SEC system satisfies the condition for baroclinic instability in this model: the meridional gradient of the mean potential vorticity changes sign around $200 \mathrm{~m}$. In particular, areas of maximum vertical shear in the subtropical basin between $24^{\circ}$ and $31^{\circ} \mathrm{S}$ are baroclinically unstable. The findings are confirmed in a stability analysis of the $2 \frac{1}{2}$ layer quasi-geostrophic model [see, e.g., Qiu, 1999]. E-folding timescales found near $64^{\circ} \mathrm{E}$ and $82^{\circ} \mathrm{E}$ ( $\sim 80$ days) compare well with baroclinic instability timescales detected in the Pacific subtropical countercurrents [Qiu, 1999; Qiu and Chen, 2004]. Given the simplicity of the two-layer model and the quality of the database in this region of the South Indian Ocean, the range of unstable wavelengths $(290-470 \mathrm{~km})$ agrees surprisingly well with estimations of the wavenumber spectra from altimetry $(\sim 440 \mathrm{~km})$. Analysis of the stability using synoptic hydrographic data along the $80^{\circ} \mathrm{E}$ section shows a range of unstable frequencies between 3.5 and 6 times/year. A similar subannual frequency is present in the SSH data along $25^{\circ} \mathrm{S}$, consistent with the 4-5 times/year Rossby wave propagation detected by Schouten et al. [2002]. Therefore, baroclinic instability of the SICC-SEC system can explain the eddy variability observed along the $25^{\circ} \mathrm{S}$ band and the fact that a large part of the variance is in the subannual frequency range. It is also worth noticing that the possibility of barotropic instability across the SICC shear was evaluated following Lipps [1963]. Assuming a simplified profile for the SICC-SEC velocity, no change in the meridional gradient of potential vorticity was detected, in 
other words, the sufficient condition for barotropic stability is satisfied.

[31] The altimetry data show high eddy kinetic energy (EKE) levels in the center of the South Indian Ocean subtropical gyre analogous to those observed along the subtropical Pacific Ocean (i.e., EKE ranges between 150 and $300 \mathrm{~cm}^{2} / \mathrm{s}^{2}$ ). The region east of Madagascar between $50^{\circ}$ and $60^{\circ} \mathrm{E}$ (see Figure 1) is a particularly highly energetic area (i.e., EKE varies from 200 up to $1000 \mathrm{~cm}^{2} / \mathrm{s}^{2}$ ). EKE variations along $25^{\circ} \mathrm{S}$ may also represent changes in the intensity and/or position of the SICC. Estimations of the EKE associated with the low frequency component of the SSH field (i.e., periods greater than 1 year) range between 20 and $70 \mathrm{~cm}^{2} / \mathrm{s}^{2}$. This suggests that a high percentage of the total EKE variability is related to mesoscale processes. Halliwell et al. [1994] suggested that a baroclinically unstable system might convert initially wavelike perturbations into large eddy structures due to a nonlinear energy cascade. It seems plausible that the variability generated locally by baroclinic instability in the subtropical Indian Ocean is connected to the eddy activity observed east and south of Madagascar [Schouten et al., 2002; de Ruijter et al., 2004; Quartly and Srokosz, 2004].

[32] High levels of EKE also exist in the South Indian Ocean over the SEC path (i.e., EKE ranges between 100 and $400 \mathrm{~cm}^{2} / \mathrm{s}^{2}$ ). The stability analysis based on the Phillips two-layer model shows that the SEC vertical shear is stable. However, an analysis of the continuously stratified system showed that the SEC in the eastern Indian Ocean is baroclinically unstable, with the largest growth rates ( $e$ folding timescales of less than 50 days) during the JulySeptember season [Feng and Wijfels, 2002]. The SEC north of Madagascar is barotropically unstable at a period of 50 days, inducing this frequency of variability in the eddy activity drifting south into the Mozambique Channel [Schott et al., 1988; Schouten et al., 2003].

[33] Finally, the EKE along $25^{\circ} \mathrm{S}$ shows a regular seasonal variation, with maxima in November and minima in May. Qiu [1999] and Qiu and Chen [2004] showed that the seasonal modulation of the EKE in the subtropical Pacific countercurrents is related to seasonal variations in the growth rate of the baroclinic waves. Analysis of seasonal velocity profiles from climatology reveals that the SICC is stronger (weaker) in summer (winter), while the SEC weakens (strengthens) due to the large-scale wind variability [Tchernia, 1980]. As a consequence, the shear of the SICC-SEC system is high in summer and winter, leading to baroclinic instability with $e$-folding timescales between 40 and 50 days in both seasons. Future studies using better quality observations of the seasonal velocity profiles as well as density sections, will need to analyze these variations and their possible relation to the annual variability of the EKE. More accurate analyses of the continuously stratified system will also require an ensemble of hydrographic observations that is not currently available for the South Indian Ocean.

[34] Acknowledgments. This research was funded by the Foundation for Earth and Life Sciences (ALW) of the Netherlands Foundation of Scientific Research (NWO) under grant 854.00.001.

\section{References}

Belkin, I. M., and A. L. Gordon (1996), Southern Ocean fronts from the Greenwich Meridian to Tasmania, J. Geophys. Res., 101, 3675-3696.
Birol, F., and R. Morrow (2001), Source of the baroclinic waves in the southeast Indian Ocean, J. Geophys. Res., 106, 9145-9160.

Birol, F., and R. Morrow (2003), Separation of the quasi-semiannual Rossby waves from the eastern boundary of the Indian Ocean, J. Mar. Res., 61, 707-723.

Chelton, D. B., R. A. deSzoeke, M. G. Schlax, K. E. Naggar, and N.Siwertz (1998), Geographical variability of the first baroclinic Rossby radius of deformation, J. Phys. Oceanogr., 28, 433-460.

Conkright, M. E., R. A. Locarnini, H. E. Garcia, T. D. O’Brien, T. P. Boyer, C. Stephens, and J. I. Antonov (2002), World Ocean Atlas 2001: Objective analyses, data statistics, and figures, CD-ROM documentation, 17 pp., Natl. Oceanogr. Data Cent., Silver Spring, Md.

de Ruijter, W. P. M., H. M. van Aken, E. J. Beier, J. R. E. Lutjeharms, R. P. Matano, and M. W. Schouten (2004), Eddies and dipoles around south Madagascar: Formation, pathways and large-scale impact, Deep Sea Res. Part I, 51, 383-400

de Ruijter, W. P. M., H. Ridderinkhof, and M. W. Schouten (2005), Variability of the southwest Indian Ocean, Philos. Trans. Math. Phys. Eng. Sci., 363, 63-76.

Donahue, K. A., and J. M. Toole (2003), A near-synoptic survey of the southwest Indian Ocean, Deep Sea Res., 50, 1893-1931.

Duchon, C. E. (1979), Lanczos filtering in one and two dimensions, J. Appl. Meteorol., 18, 1016-1022.

Fang, F., and R. Morrow (2003), Evolution, movement and decay of warmcore Leeuwin Current eddies, Deep Sea Res., 50, 2245-2261.

Feng, F., and S. Wijffels (2002), Intraseasonal variability of the South Equatorial Current of the east Indian Ocean, J. Phys. Oceanogr., 32, $265-277$.

Gordon, A. L. (1995), WHP Indian Ocean I9N, Int. WOCE Newsl., 20, 2627.

Gründlingh, M. L. (1995), Tracking eddies in the southeast Atlantic and southwest Indian oceans with TOPEX/Poseidon, J. Geophys. Res., 100, 24,977-24,986.

Halliwell, G. R., Jr., G. Peng, and D. B. Olson (1994), Stability of the Sargasso Sea Subtropical Frontal Zone, J. Phys. Oceanogr., 24, $1166-$ 1183 .

Lipps, F. B. (1963), Stability jets in a divergent bartropic fluid, J. Atmos. Sci., 20, 120-129.

Lutjeharms, J. R. E. (1976), The Agulhas Current system during the northeast monsoon season, J. Phys. Oceanogr., 6, 665-670.

Lutjeharms, J. R. E. (1988), Remote sensing corroboration of the retroflection of the East Madagascar Current, Deep Sea Res., Part A, 35, $2045-2050$

Morrow, R., and F. Birol (1998), Variability in the southeast Indian Ocean from altimetry: Forcing mechanisms for the Leeuwin Current, J. Geophys. Res., 103, 18,529-18,544.

Palastanga, V., P. J. van Leeuwen, and W. P. M. de Ruijter (2006), A link between low-frequency mesoscale eddy variability around Madagascar and the large-scale Indian Ocean variability, J. Geophys. Res., 111, C09029, doi:10.1029/2005JC003081.

Pedlosky, J. (1987), Geophysical Fluid Dynamics, 710 pp., Springer, New York.

Perigaud, C., and P. Delecluse (1992), Annual sea level variations in the southern tropical Indian Ocean from Geosat and shallow water simulations, J. Geophys. Res., 97, 20,169-20,178.

Phillips, N. A. (1954), Energy transformations and meridional circulations associated with simple baroclinic waves in a two-level, quasi-geostrophic model, Tellus, 6, 273-286.

Qiu, B. (1999), Seasonal eddy field modulation of the North Pacific Subtropical Countercurrent: TOPEX/Poseidon observations and theory, J. Phys. Oceanogr., 29, 2471-2486.

Qiu, B., and S. Chen (2004), Seasonal modulations in the eddy field of the South Pacific Ocean, J. Phys. Oceanogr., 34, 1515-1527.

Quartly, G. D., and M. A. Srokosz (2004), Eddies in the southern Mozambique Channel, Deep Sea Res., Part II, 51, 69-83.

Reid, J. L. (2003), On the total geostrophic circulation of the Indian Ocean: Flow patterns, tracers, and transports, Prog. Oceanogr., 56, 137-186.

Schott, F., M. Fieux, J. Kindle, J. Swallow, and R. Zantopp (1988), The boundary currents east and north of Madagascar: 2. Gesotrophic direct measurements and model comparisons, J. Geophys. Res., 93, 49634974

Schouten, M. W., W. P. M. de Ruijter, and P. J. van Leeuwen (2002), Upstream control of Agulhas Ring shedding, J. Geophys. Res., 107(C8), 3109, doi:10.1029/2001JC000804.

Schouten, M. W., W. P. M. de Ruijter, P. J. van Leeuwen, and H. Ridderinkhof (2003), Eddies and variability in the Mozambique Channel, Deep Sea Res., Part II, 50, 1987-2003.

Stammer, D. (1997), Global characteristics of ocean variability estimated from regional TOPEX/Poseidon altimeter measurements, J. Phys. Oceanogr., 27, 1743-1769. 
Stramma, L. (1992), The South Indian Ocean Current, J. Phys. Oceanogr, $22,421-430$.

Stramma, L., and J. R. E. Lutjeharms (1997), The flow field of the subtropical gyre of the south Indian Ocean, J. Geophys. Res., 102, 53305513.

Takeuchi, K. (1986), Numerical study of the seasonal variations of the Subtropical Front and the Subtropical Countercurrent, J. Phys. Oceanogr., 16, 919-926.

Talley, L. D., and M. O. Baringer (1997), Preliminary results from WOCE hydrographic sections at $80^{\circ} \mathrm{E}$ and $32^{\circ} \mathrm{S}$ in the central Indian Ocean, Geophys. Res. Lett., 24, 2789-2792.

Tchernia, P. (1980), Descriptive Regional Oceanography, Pergamon Mar. Ser., vol. 3, 253 pp., Elsevier, New York.
Wyrtki, K. (1971), Oceanographic Atlas of the Interanational Indian Ocean Expedition, 531 pp., Natl. Sci. Found., Washington, D. C.

Xie, S. P., H. Annamalai, F. A. Schott, and J. P. McCreary Jr. (2002), Structure and mechanisms of south Indian Ocean climate variability, J. Clim., 15, 864-878.

W. P. M. de Ruijter, V. Palastanga, and P. J. van Leeuwen, Institute for Marine and Atmospheric Research, Utrecht University, NL-3508 TA Utrecht, Netherlands. (v.palastanga@phys.uu.nl)

M. W. Schouten, Royal Netherlands Institute for Sea Research, NL-1759 AB, Texel, Netherlands. 